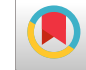

\title{
Prevalence of Depression Among Primary Caregivers of Stroke Survivors in Nigeria
}

\author{
Umeonwuka Chuka Ifeanyi, ${ }^{1,}$ Fatima Shehu Sa'ad, ${ }^{1}$ Ogbueche Chukwukdi Martin, ${ }^{2}$ Maduagwu \\ Stanley Monday, ${ }^{3}$ and Nwachukwu Juliet Onyinyechukwu ${ }^{4}$ \\ ${ }^{1}$ Department of Medical Rehabilitation, College of Medical Science, University of Maiduguri, Maiduguri, Borno State, Nigeria \\ ${ }^{2}$ Department of Physiotherapy State specialist Hospital, Okitipupa, Ondo State, Nigeria \\ ${ }^{3}$ Department of Physiotherapy, University of Maiduguri Teaching Hospital, Maiduguri, Borno State, Nigeria \\ ${ }^{4}$ General Hospital, Nyanya Abuja-FCT, Nigeria \\ "Corresponding author: Umeonwuka Chuka Ifeanyi, Department of Medical Rehabilitation, College of Medical Sciences, University of Maiduguri, Maiduguri, Borno State, \\ Nigeria. Tel: +23-47065492665, E-mail: chuquespt@unimaid.edu.ng
}

Received 2017 December 19; Revised 2018 March 15; Accepted 2018 March 17.

\section{Abstract}

Background: Stroke has a great adverse effect not only on the lives of stroke survivors but also on the informal caregivers, as they provide care ranging from assistance in activities of daily living, leading to a high risk of depression and other psychological morbidities.

Objectives: This study explored the prevalence of depression and associated factors among primary caregivers of stroke survivors in Nigeria.

Methods: A cross sectional survey on the prevalence of depression among primary caregivers of stroke survivors was conducted at selected hospitals in Maiduguri, Nigeria. A sample of convenience was used to recruit participants in this study. The Beck depression inventory was used to screen for depression. Data form and patients folders were used to obtain socio-demographics and clinical characteristics of participants and stroke survivors.

Result: A total of 115 primary caregivers participated, out of which $53 \%$ were male and $47 \%$ were female. The mean age and overall beck depression inventory score were $30.78 \pm 9.66$ and $15.42 \pm 7.84$, respectively. The overall prevalence of depression was found to be $46.1 \%$. Type of stroke $(\mathrm{P}=0.03)$ and post stroke duration $(\mathrm{P}=0.02)$ of stroke survivors cared for was found to be associated with depression among caregivers of stroke survivors.

Conclusions: Caring for the patients with stroke presents increased in the psychological impact of caregiving for stroke survivors, it is therefore recommended that information, education, and support should be provided to primary caregivers as they are key in sustaining rehabilitation gains and long term overall well-being of stroke survivors.

Keywords: Depression, Caregivers, Stroke

\section{Background}

Globally, stroke has been reported as one of the leading causes of mortality and disability (1). Every year, about 15 million of the world population suffers from stroke, out of which around 33\% die and 33\% become disabled permanently (2). It is projected in the next 15 years that a great majority of stroke incidence will occur in people living in low and middle-income countries like to Nigeria (3). In 2005, deaths, as a result of stroke in low-income and middle-income countries, were 57 million with a mortality in Nigeria reported as 126 per 100,000 (4). Stroke is a long-standing and debilitating condition that has a profound negative influence on not just the sufferers, but also on their families and distort to varying degree activities of daily life such as self-care, employment, and leisure of the sufferers (5). Stroke has a great influence not only on stroke survivors, but also on their caregivers (6). Primary caregivers are the individuals who take cardinal care for someone who cannot care for themselves, usually a family member or friend following the onset of a debilitating illness (7). The burden of long-term care for stroke survivors, as a result of stroke, are largely undertaken by the primary caregiver, which in the most instance is a family member of the patient; this could also eventually impoverish the family due to reduced working hours in income generating activities (8). Caregivers of stroke can therefore be considered the 2nd victim of the disease, as they are often not supported by the health system or integrated into the rehabilitation process (9). The burden of caring for stroke sur- 
vivors place the caregivers at risk of psychological morbidity (10).

Depression is a disorder characterized by sadness, loss of interest in activities, and decreased energy (11) and has been widely explored among primary caregivers, especially among females and adolescents (12). The prevalence of depression is reported to be in preponderance among caregivers of stroke patients than in stroke survivors, with prevalence among stroke survivors ranging from $30 \%-52 \%$ of depression in stroke caregivers (13).

Pooled global prevalence of depressive symptoms among caregivers of stroke survivors is estimated to be $40.2 \%$ (14) in 2016. In a Finnish study conducted by Berg and colleagues, the prevalence of depression among caregivers of stroke survivors was reported to be between $30 \%$ - 33\% (15). Also, $33.57 \%$ to $42.16 \%$ of all caregivers were depressed as reported in an Iranian population (16). In a survey in a Chinese population, $71 \%$ of stroke caregivers was reported to have experienced depressive symptoms (17).

In Nigeria, there has been growing concern about the burden of stroke and stroke-related side effects in different parts of the country among hospital and community in-dwelling population groups (18-20). There is, however, growing documentation of the caregiving burden, poor caregiver outcomes, lack of caregiver support, and equivocal success aimed at ameliorating the caregiving burden, which may affect mental health (21). Hence, the emphasis in stroke rehabilitation needs to shift from patient-focused approach to a holistic combined patient-caregiver-focused approach, which is necessary due to the fact that primary caregivers are central in sustaining rehabilitation gains of stroke survivors (21).

However, there seems to be a paucity of regional data on the prevalence of depression among primary caregivers of stroke survivors in north eastern Nigeria. With the foregoing in mind, this study was conceived to identify the prevalence and associated factors of depression among primary caregivers of stroke survivors.

\section{Methods}

\subsection{Participants}

The participants for this study were primary caregivers of stroke survivors attending physiotherapy clinics at selected hospitals in Maiduguri, North-eastern Nigeria.

\subsection{Inclusion and Exclusion Criteria}

The inclusion criteria of participants into this study include: caregivers of stroke survivors ability to verbally communicate in the English language and caregivers of stroke survivors that actively participate in caregiving of the stroke survivor for at least 6 hours weekly. Caregivers of stroke survivors who were less than 18 years and $\geq 65$ years as well as caregivers with a physical disability were excluded from this study.

\subsection{Study Design}

This study was a cross-sectional survey of primary caregivers of stroke survivors attending physiotherapy clinics at selected hospitals in Maiduguri, Nigeria. A sample of convenience was used to recruit caregivers of stroke survivors from the selected study centers in this study.

\subsection{Study Setting}

This study was conducted at the University of Maiduguri Teaching Hospital (UMTH), State Specialist Hospital Maiduguri, and the Umaru Shehu Ultra-Modern Hospital Maiduguri, North-eastern Nigeria.

\subsection{Instrumentation}

\subsubsection{The Beck Depression Inventory:}

Beck depression inventory (BDI) was used to screen depression among participants.

BDI is a 21-item, self-report rating inventory that measures symptoms and behaviour of depression (22) using a four-point scale, which ranges from 0 (symptoms not present) to 3 (symptoms very intense). Completion time for the BDI is approximately 10 minutes. The BDI consists of systematically structured questions that assess mood, pessimism, and sense of failure, self-dissatisfaction, guilt, punishment, self-dislike, self-accusation, suicidal ideas, crying, irritability, social withdrawal, body image, work difficulty, insomnia, fatigue, appetite, weight loss, bodily preoccupation, and loss of libido. Items 1 to 13 assess symptoms that are psychological in nature, while items 14 to 21 assess physical symptoms peculiar to depression. Scores from 0 to 10 represent normal, scores from 11 to 17 indicates mild mood disturbance, scores from 17 to 20 indicate borderline clinical depression, scores from 21 to 30 indicate moderate depression, scores from 31-40 indicates severe depression, and scores over 40 indicates extreme depression. The BDI has also shown high construct validity with the medical symptoms it measures. Internal consistency for the BDI ranges from 0.73 to 0.92 with a mean of 0.86 (20). The BDI demonstrate high internal consistency with alpha coefficients of .86 and .81 for psychiatric and non-psychiatric population (23).

\subsubsection{Data Form}

Participant data form was used to collect information about socio-demographic characteristics of the caregivers 
of stroke survivors. The form was developed by the researcher and was used to obtain information on participant' age, gender, occupational status, marital status, educational status, and also the relationship with the stroke survivor.

\subsubsection{Patients Hospital Case Folder}

The patients' (stroke survivors) hospital case folder was used to obtain information about the clinical characteristics of the stroke survivors. Clinical data of stroke survivors obtained included post-stroke duration, side of stroke affectation and type of stroke.

\subsection{Data Collection Procedure}

Ethical Research Committee of the University of Maiduguri Teaching Hospital gave approval for the study. The permission of the departments of physiotherapy at the selected hospitals was also sought and obtained. The informed consent form was signed and obtained from all of the subjects. Study data form and Beck depression inventory were administered to the participants that met the inclusion criteria of the study to complete at the selected sites and the researcher obtained patients clinical characteristics from the patients' folders.

\subsection{Data Analysis}

Descriptive statistics of mean, standard deviation, frequency, and percentages were used to summarize the data. Chi square test was used to assess the difference in prevalence of depression among participants. This data summary was performed utilizing statistical package for social sciences (SPSS), (Windows version 20.0).

\section{Results}

A total of 136 caregivers of stroke survivors that met the inclusion criteria for this study were approached to participate in this study. However, a total of 115 caregivers of stroke survivors consented to participate in this study. The overall depression prevalence rate of informal caregivers of stroke was $46.1 \%$. The mean age of the caregivers that participated in this study was $30.78 \pm 9.66$ years (age range $=19-59$ years). A total of $53 \%$ of the caregivers were male while $47 \%$ were females. Of the stroke surviors, 76 caregivers were children, 16 caregivers were siblings of the stroke survivor, 5 caregivers were a spouse, and 7 caregivers were friends of stroke survivors (Table 1).

A total of 32 caregivers reported to be normal, 30 reported mild mood disturbance, 20 caregivers reported borderline clinical depression, 29 reported moderate depression, and 4reported severe depression. None of the caregivers reported extreme depression (Table 2).

\begin{tabular}{|c|c|}
\hline Variable & No. $(\%)$ \\
\hline \multicolumn{2}{|l|}{ Age, $y$} \\
\hline $19-35$ & $86(74.8)$ \\
\hline $36-55$ & $27(23.5)$ \\
\hline$\geq 55$ & $2(1.7)$ \\
\hline \multicolumn{2}{|l|}{ Gender } \\
\hline Male & $61(53.0)$ \\
\hline Female & $54(47.0)$ \\
\hline \multicolumn{2}{|l|}{ Employment status } \\
\hline Employed & $34(29.6)$ \\
\hline Unemployed & $38(33.0)$ \\
\hline Student & $43(37.4)$ \\
\hline \multicolumn{2}{|l|}{ Educational Status } \\
\hline Primary & $6(5.2)$ \\
\hline Secondary & $17(14.8)$ \\
\hline Tertiary & $65(56.5)$ \\
\hline Quranic & $21(18.3)$ \\
\hline None & $21(18.3)$ \\
\hline \multicolumn{2}{|c|}{ Relationship with stroke survivor } \\
\hline Child & $76(66.1)$ \\
\hline Sibling & $16(13.9)$ \\
\hline Spouse & $5(4.3)$ \\
\hline Friend & $7(6.1)$ \\
\hline Others & $11(9.6)$ \\
\hline \multicolumn{2}{|l|}{ Side of affectation } \\
\hline Left & $63(54.8)$ \\
\hline Right & $52(45.2)$ \\
\hline \multicolumn{2}{|l|}{ Type of stroke } \\
\hline Ischaemic & $70(60.9)$ \\
\hline Haemorrhagic & $45(39.1)$ \\
\hline \multicolumn{2}{|c|}{ Post-stroke duration, mo } \\
\hline $19-12$ & $85(73.9)$ \\
\hline $13-24$ & $18(15.7)$ \\
\hline$>25$ & $12(10.4)$ \\
\hline
\end{tabular}

Gender $(\mathrm{P}=0.24)$, age $(\mathrm{P}=0.32)$, employment status $(P=0.28)$, educational level $(P=0.73)$, the relationship of care-giver with the stroke survivor $(\mathrm{P}=0.42)$, and stroke survivors' sides of affectation $(\mathrm{P}=0.69)$ was found to not be associated with depression of caregiver of stroke. However, type of stroke $(\mathrm{P}=0.03)$ and post stroke duration of the stroke survivors $(\mathrm{P}=0.02)$ cared for was found to be as- 


\begin{tabular}{lc}
\hline Table 2. Prevalence of Depression Among Caregivers of Stroke Survivors $(\mathrm{n}=115)^{\mathrm{a}}$ \\
\hline Type of Depression & No. $(\%)$ \\
\hline Normal & $32(27.8)$ \\
\hline Mild mood disturbances & $30(27.1)$ \\
\hline Borderline clinical depression & $20(17.4)$ \\
\hline Moderate depression & $29(25.2)$ \\
\hline Severe depression & $4(3.5)$ \\
\hline
\end{tabular}

${ }^{\mathrm{a}}$ Normal and mild mood depression = Considered as not depressed .

sociated with depression among caregivers of stroke survivors (Table 3 ).

\section{Discussion}

The success of the rehabilitation process after a stroke involves supportive caregivers who provide direct assistance. Caregiver burden is a multidimensional construct, which involves not only objective burden (caregiving tasks and time), but also the caregivers' subjective report of the care they provide in terms of emotional cost of caregiving involvement hence needs to be integrated into the rehabilitation process.

In our study, the overall depression prevalence rate of informal caregivers of stroke was $46.1 \%$. One-fourth of the caregivers of stroke survivors had moderate depression and 3.5\% reported severe depression, which was contrary to the findings of a study in Ghana by Abeasi and Osafo (24) where $84.0 \%$ caregivers reported mild mood disturbance, $12.0 \%$ borderline depression, $4.0 \%$ moderate depression, and none reported severe depression. However, our study was consistent with other studies $(25,26)$ that reported a higher prevalence of depression among caregivers of stroke survivors. In our study population, half of the caregivers were children of the stroke survivor and are often fraught with social isolation and stigma associated with taking care of the disabled person in our milieu and have little or no leisure time, hence predisposing the caregiver to decline in mental health. In addition, it is possible dissatisfaction from financial lack as a result of not engaging in a paid job caused by disability of stroke to the survivor and the inability of the caregiver to engage fully in income generating activity as a result of the caregiving demands may also have contributed to the high preponderance of depression among the caregivers of stroke survivors in our study. However, the previous study has reported financial constraint to have a significant positive relationship with depression (24).

The sociodemographic characteristic of the caregiver of stroke survivors in our study (gender, age, employment status, educational level, relationship with the stroke survivor, and depression) was not significantly associated with depression. This finding is in agreement with previous studies that reported gender (27), age (24), employment status (28), and educational level of caregivers of post stroke survivors (29) was not associated with depression amongst caregivers of stroke.

Post stroke duration of stroke survivor had a significant association with depression of caregivers of stroke survivors. In our study, caregivers of stroke survivors in the early phase of recovery had a higher preponderance of depression. This observation is not surprising due to the fact that the neurological recovery of stroke patients has been reported to significantly improve within the 3week period immediately after a stroke, and the functional recovery may continue to improve up to 18 months after stroke (30). Hence stroke patients who are at different phases of stroke recovery after a stroke generally have different severity and manifestation of neurological deficits as well as different levels of functional impairments (31-33), translating to diverse needs for caregiving and demand on the caregiver. Furthermore, at the early phase of caregiving for stroke survivors, caregivers are not prepared for the role of caregiving and hence not well adjusted for the role of caregiving, which often has psychological implications for the caregiver. (34). This corroborates a study by Berg and colleagues that reported the stronger presence of depressive symptoms among caregivers of stroke survivors at the acute phase of a stroke (15).

In addition, the type of stroke was shown to have a significant association with depression in our study. In our study ischaemic stroke patients' caregivers were observed to have a higher prevalence of depression. This is not unanticipated as it has been reported in the literature that patients with haemorrhagic stroke have shown better neurological and functional prognoses than ischaemic stroke survivors (35). The poor functional prognoses in ischaemic stroke survivors will result in more functional limitation that necessitates much dependence and assistance from the caregivers (36) precipitating long-term and more demanding care, which impoverishes the caregivers both physically and psychologically (8) making them vulnerable to depression.

\subsection{Conclusions}

There is therefore a need for a paradigm shift in the rehabilitation of stroke survivors to include caregivers. Coping strategies and education of caregivers aimed at ameliorating the burden of caring for the stroke survivor should be part of the rehabilitation process. Further studies on the prevalence of depression among primary caregivers of stroke survivors in different regions of Nigeria is needed. In addition, a future study on effective strategies capable of 


\begin{tabular}{|c|c|c|c|c|}
\hline Variable & Depressed & Non-Depressed & $\chi^{2}$ & PValue \\
\hline Gender & & & 1.362 & 0.24 \\
\hline Male & $25(41.1)$ & $36(59.0)$ & & \\
\hline Female & $28(51.9)$ & $26(48.1)$ & & \\
\hline Age & & & 2.282 & 0.32 \\
\hline $19-35$ & $42(48.0)$ & $44(51.2)$ & & \\
\hline $36-55$ & $11(40.7)$ & $16(59.3)$ & & \\
\hline$>55$ & $0(0.0)$ & $2(100)$ & & \\
\hline Employment status & & & 2.567 & 0.28 \\
\hline Employed & $12(35.3)$ & $22(64.7)$ & & \\
\hline Unemployed & $18(47.4)$ & $20(52.6)$ & & \\
\hline Student & $23(53.5)$ & $20(46.5)$ & & \\
\hline Educational kevel & & & 2.029 & 0.73 \\
\hline Primary & $2(33.3)$ & $4(66.7)$ & & \\
\hline Secondary & $8(47.1)$ & $9(52.9)$ & & \\
\hline Tertiary & $31(47.7$ & $34(52.3)$ & & \\
\hline Qur'anic & $8(38.1)$ & $13(61.90)$ & & \\
\hline None & $4(66.7)$ & $2(33.3)$ & & \\
\hline Relationship with stroke survivors & & & 3.906 & 0.42 \\
\hline Child & $35(46.1)$ & $41(53.9)$ & & \\
\hline Sibling & $9(56.2)$ & $7(43.8)$ & & \\
\hline Spouse & $3(60.0)$ & $2(40.0)$ & & \\
\hline Friend & $3(60.0)$ & $6(85.7)$ & & \\
\hline Others & $5(45.5)$ & $6(54.5)$ & & \\
\hline Post-stroke duration, mo & & & 7.477 & $0.02^{* *}$ \\
\hline $1-12$ & $33(38.8)$ & $52(61.2)$ & & \\
\hline $13-24$ & $11(61.1)$ & $7(38.9)$ & & \\
\hline$\geq 25$ & $9(75.0)$ & $3(25.0)$ & & \\
\hline Side of affectation & & & 0.151 & 0.69 \\
\hline Left & $28(44.4)$ & $35(55.6)$ & & \\
\hline Right & $25(48.1)$ & $27(51.9)$ & & \\
\hline Type of stroke & & & 4.840 & $0.03^{* *}$ \\
\hline Ischaemic & $38(54.3)$ & $32(55.6)$ & & \\
\hline Haemorrhagic & $15(33.3)$ & $30(66.7)$ & & \\
\hline
\end{tabular}

${ }^{\mathrm{a}}$ Values are expressed as No. (\%).

appreciably reducing the prevalence of depression among primary caregivers of stroke survivors is also urgently required.

\subsection{Limitation of Study}

An important limitation of this study was the nonprobability sampling technique utilized in recruiting par- ticipants, which could have resulted in selection bias and may have negatively affected the generalizability of findings. Also, our study did not put into consideration the severity of the disability of stroke survivors and the presence or absence of other disabling conditions such as musculoskeletal problems (not as a result of the stroke) among stroke survivors in this study, which may negatively affect 
the dependence of stroke survivors on their care-giver.

\section{Acknowledgments}

We express our profound gratitude to the head of physiotherapy department of the University of Maiduguri Teaching hospital, Maiduguri, Nigeria. We also appreciate the participants that agreed to participate in this study.

\section{Footnote}

Conflict of Interest: The authors declare that they have no conflicts of interest.

\section{References}

1. World Health Organization. The atlas of heart disease and stroke. 2010. Available from: http://www.who.int/cardiovascular-diseases/ resources/atlas/en.

2. World Health Organization. World Health Organization report. Geneva; 2007. Available from: http://www.who.int/whr/2007/whr07en.pdf.

3. Mathers CD, Loncar D. Projections of global mortality and burden of disease from 2002 to 2030.PLoS Med.2006;3(11). e442. doi:10.1371/journal.pmed.0030442. [PubMed: 17132052].

4. Strong K, Mathers C, Bonita R. Preventing stroke: saving lives around the world. Lancet Neurol. 2007;6(2):182-7. doi: 10.1016/S14744422(07)70031-5. [PubMed: 17239805]

5. Corr S. Life after stroke: the characteristic of those Aged 18-55years and an evaluation of a support service. Swansea: Univ of Wales; 2003.

6. Rigby H, Gubitz G, Phillips S. A systematic review of caregiver burden following stroke. Int J Stroke. 2009;4(4):285-92. doi: 10.1111/j.17474949.2009.00289.x. [PubMed:19689757].

7. Barbic SP, Mayo NE, White CL, Bartlett SJ. Emotional vitality in family caregivers: content validation of a theoretical framework. Qual Life Res. 2014;23(10):2865-72. doi: 10.1007/s11136-014-0718-4. [PubMed: 24853533].

8. Pandian JD, Srikanth V, Read SJ, Thrift AG. Poverty and stroke in India: a time to act. Stroke. 2007;38(11):3063-9. doi: 10.1161/STROKEAHA.107.496869. [PubMed: 17954905].

9. Bartolo M, De Luca D, Serrao M, Sinforiani E, Zucchella C, Sandrini G. Caregivers burden and needs in community neurorehabilitation. Rehabil Med. 2010;42(9):818-22. doi: 10.2340/16501977-0612. [PubMed: 20878041].

10. Scholte op Reimer WJ, de Haan RJ, Rijnders PT, Limburg M, van den Bos GA. The burden of caregiving in partners of long-term stroke survivors. Stroke. 1998;29(8):1605-11. [PubMed: 9707201].

11. World Health Organization. The World Health Report 2001: Mental Health New understanding, New Hope. 2001.

12. Douglas SL, Daly B. Caregivers of long-term ventilator patients, physical and psychological outcomes clinical investigation. 2003. Available from: http://www.article/mi_m0984.

13. Gonzalez C, Bakas T. Factors associated with stroke survivor behaviors as identified by family caregivers. Rehabil Nurs. 2013;38(4):202-11. doi: 10.1002/rnj.85. [PubMed: 23686515].

14. Loh AZ, Tan JS, Zhang MW, Ho RC. The Global Prevalence of Anxiety and Depressive Symptoms Among Caregivers of Stroke Survivors. J Am Med Dir Assoc. 2017;18(2):111-6. doi: 10.1016/j.jamda.2016.08.014. [PubMed: 27742585].

15. Berg A, Palomaki H, Lonnqvist J, Lehtihalmes M, Kaste M. Depression among caregivers of stroke survivors. Stroke. 2005;36(3):639-43. doi: 10.1161/01.STR.0000155690.04697.c0. [PubMed: 15677575].
16. Koohestani HR, Baghcheghi N. The Prevalence of Depression among Caregivers of Stroke Survivors and Related Factors in Arak. Iran J Epidemiol. 2012;8(3):66-72.

17. Guo Y, Liu YJ. Family functioning and depression in primary caregivers of stroke patients in China. Int J Nurs Sci. 2015;2(2):184-9.

18. Danesi M, Okubadejo N, Ojini F. Prevalence of stroke in an urban, mixed-income community in Lagos, Nigeria. Neuroepidemiology. 2007;28(4):216-23. doi:10.1159/000108114. [PubMed: 17851261].

19. Wahab KW. The burden of stroke in Nigeria. Int J Stroke. 2008;3(4):2902. doi: 10.1111/j.1747-4949.2008.00217.x. [PubMed: 18811746].

20. Enwereji KO, Nwosu MC, Ogunniyi A, Nwani PO, Asomugha AL, Enwereji EE. Epidemiology of stroke in a rural community in Southeastern Nigeria. Vasc Health Risk Manag. 2014;10:375-88. doi 10.2147/VHRM.S57623. [PubMed: 25028556]

21. Blake H, Lincoln NB, Clarke DD. Caregiver strain in spouses of stroke patients. Clin Rehabil.2003;17(3):312-7. doi: 10.1191/0269215503cr613oa. [PubMed: 12735539].

22. Beck AT. An Inventory for Measuring Depression. Arch General Psychiatr.1961;4(6):561. doi:10.1001/archpsyc.1961.01710120031004.

23. Beck AT, Steer RA, Carbin MG. Psychometric properties of the Beck Depression Inventory: Twenty-five years of evaluation. Clin Psychol Rev. 1988;8(1):77-100. doi: 10.1016/0272-7358(88)90050-5.

24. Abeasi DA, Osafo J. Depression among family caregivers of stroke survivors in Ghana. Int J Sci Res. 2017;6:799-804.

25. Grant JS, Weaver M, Elliott TR, Bartolucci AR, Newman Giger J. Sociodemographic, physical and psychosocial factors associated with depressive behaviour in family caregivers of stroke survivors in the acute care phase. Brain Inj. 2004;18(8):797-809. doi: 10.1080/02699050410001671766. [PubMed: 15204320].

26. Khalid T, Kausar R. Depression and quality of life among caregivers of people affected by stroke. Asia Pac Disabil Rehabil J. 2008;19(2):103-10.

27. Balhara YS, Mathur S, Sharma S, Verma R. A study of predictors of anxiety and depression among stroke patient-caregivers. J Mid-Life Health. 2012;3(1):31. doi: 10.4103/0976-7800.98815.

28. Markey E. The Impact of Caregiving on the Development of Major Depressive Disorder and Generalized Anxiety Disorder. J Eur Psychol Students. 2015;6(1):17-24. doi: 10.5334/jeps.cn.

29. King RB, Hartke RJ, Houle TT. Patterns of relationships between background characteristics, coping, and stroke caregiver outcomes. Top Stroke Rehabil. 2010;17(4):308-17. doi: 10.1310/tsr1704-308. [PubMed 20826419].

30. National Stroke Association. The Road Ahead: A Stroke Recovery Guide. Denver, Colo: The National Stroke Association; 1986.

31. Schulz R, Tompkins CA, Rau MT. A longitudinal study of the psychosocial impact of stroke on primary support persons. Psychol Aging. 1988;3(2):131-41. [PubMed: 3268251].

32. Spencer KA, Tompkins CA, Schulz R. Assessment of depression in patients with brain pathology: the case of stroke. Psychol Bull. 1997;122(2):132-52. [PubMed: 9283297].

33. Kelly-Hayes M. Time intervals, survival, and destination. Three crucial variables in stroke outcome research. Stroke.1990;21(9 Suppl):II24-6.

34. Chang HY, Chiou CJ, Chen NS. Impact of mental health and caregiver burden on family caregivers' physical health. Arch Gerontol Geriatr. 2010;50(3):267-71. doi: 10.1016/j.archger.2009.04.006. [PubMed: 19443058]

35. Paolucci S, Antonucci G, Grasso MG, Bragoni M, Coiro P, De Angelis D, et al. Functional outcome of ischemic and hemorrhagic stroke patients after inpatient rehabilitation: a matched comparison. Stroke. 2003;34(12):2861-5. doi: 10.1161/01.STR.0000102902.39759.D3. [PubMed: 14615613].

36. Centers for Disease Control Prevention. Characteristics and health of caregivers and care recipients-North Carolina, 2005. MMWR Morbidity Mortality Week Rep. 2007;56(21):529. 